\title{
モデル予測制御を用いた晒白色度の多变数制御
}

\author{
王子製紙株式会社 春日井工場 施設部電気計装課 $\bigcirc$ 川 北 真 裕 \\ 王子製紙株式会社 製紙技術研究所 森 芳 立 \\ 横河電機株式会社 産業ソリューション事業本部 西 村 淳
}

\section{A Multivariable Brightness Control of Bleaching Process by Model Predictive Control}

\author{
Masahiro Kawakita \\ Kasugai Mill, Oji Paper Co., Ltd. \\ Yoshitatsu Mori \\ Pulp and Paper Research Laboratory, Oji Paper Co., Ltd. \\ Jun Nishimura \\ Industrial Solutions Business Headquarters, Yokogawa Electric Corporation
}

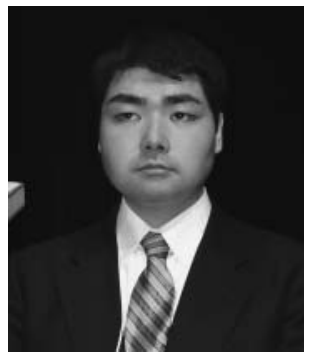

川北真裕

The needs of the optimal control for paper mills are increasing. The optimal control can reduce the cost and increase the productivity. MPC (Model Predictive Control) is a controller which can control the multivariable and long delay time system optimally, so the MPC is suitable for the optimal control of the paper plant.

We applied the MPC system to the soft wood bleaching process of the KASUGAI Mill for the brightness control. The purpose of the brightness control is to stabilize the discharged final pulp brightness and to decrease the chemical cost.

The sequence flow of the target bleaching process consists of [D 1-E/O-P-D 2] stages. At first, we applied this MPC system to the D 2 stage of the bleaching process to verify the controllability of MPC to bleach process. As the result, we could see the contribution effect of the MPC system to stabilize the final brightness. The next target is to expand and to improve the MPC system to cover the whole process of the bleach plant.

分類： $V_{1}$ 計装・制御システム一般， $V_{2}$ 紙パルプ工程制御システム

\section{1.はじめに}

近年，紙パ業界を取り巻く環境の変化から，より一層のコ スト削減が求められている。これを計装の面から支えるのは 制御の更なる自動化と効率化である。つまりプラント全体の 制御を最適化することにより，コストの削減を目指すという 考え方である。しかし多入力多出力系であるプラント全体の 最適化を目的とするような制御を PID で扱うには限界があ り，また時定数やむだ時間が長い系の制御も PIDでは難し い。特に紙パプロセスにおいては，むだ時間が長いプロセス が多く, PID 制御のみでは制御性に限界がある場合が多い。 以上より，紙パのプラント全体を視野に入れた最適な制御を 行うためには，多入力多出力かつ大きなむだ時間をもつ系を 扱うことのできる制御アルゴリズムが必要となる。

このような要求に応える制御アルゴリズムの一つとしてモ デル予測制御（Model Predictive Control；MPC）が提案さ れており，他の産業分野で既に多くの実績を上げている。
近年当工場の晒設備もすべて ECF 化されたが, ECF 晒工 程における主要な晒薬品である二酸化塩素 $\left(\mathrm{ClO}_{2}\right)$ のコスト 高がひとつのネックとなっている。そこで我々は ECF 晒プ ラントへモデル予測制御を適用することにより，プラントの 運転状態を維持しつつ経済運転を達成することを目指してい る。本稿ではこの取組みについて紹介する。

\section{2. モデル予測制御について}

MPC は制御器の内部に制御対象の多変数入出力モデルを 持つ。MPC はこのモデルを用いて所与の外乱に対する系の 将来の出力を予測し，これと目標とのズレを最小にするよう に入力の設定を決める。このとき予測された出力と実際の出 力との間にズレが生じた場合, 出力はフィードバック修正機 構により逐次修正されていく。これが MPCの基本的な動作 である。よって, MPCにおける制御器の設計とは, MPCの アルゴリズムが構築済みであるならば，制御機能を満たすた めのモデルの構築に他ならない。 
今回 MPC 制御パッケージとして横河電機株製の「Exas$\mathrm{moc} 」 を($ 使用した1)。このオンラインコントローラモジュー ルから既設の単ループ制御へと設定值を落とし込むことによ り既存の制御を利用して多変数制御および同時最適化を行う ことを可能にする。また Exasmocにはオンラインコントロ ーラモジュールに加え, プロセスモデル作成ツール AIDAPro, コントローラ設計・シミュレーションッール SMOCpro と，モデリングから制御まで一貫して取り扱う環 境が提供されている。

\section{3. 春日井工場 3 BL 晒設備概要}

今回 MPCの適用を実施したのは当春日井工場 $3 \mathrm{BL}$ 設備 である（図 1)。3 BL は日産最大 $700 \mathrm{ADT} の \mathrm{~N}$ 系パルプの $\mathrm{ECF}$ 晒設備である。シーケンスは D 1-E/O-P-D 2 であり， このうち D 2 段は D 2 a 塔, D 2 b 塔の 2 塔からなる 4 段 5 塔設備である。初段の $\mathrm{D} 1$ 段で $\mathrm{ClO}_{2}$ によりリグニンの分解 を行う。分解されたリグニンを次の $\mathrm{E} / \mathrm{O}$ 段においてアルカ リ下で抽出・除去し, 同時に酸素で漂白を進める。P 段は過 酸化水素漂白段である。最後に D 2 段の $\mathrm{ClO}_{2}$ 漂白で仕上げ る。尚, 原料白色度はメッツオオートメーション社製コルメ ック白色度計でオンライン測定している。

日産 600ADT のとき, 各塔の原料滞留時間は D 1 段と E/ $\mathrm{O}$ 段は各々約 60 分，P段は約 75 分，D 2 段では 2 塔分ある ため約 170 分にも上る。すなわち各段での薬液添加から白色 度上昇の結果が得られるまで，最低でもそれだけのむだ時間 があるということになる。

\section{4. $3 \mathrm{BL}$ へのモデル予測制御の適用}

$3 \mathrm{BL}$ において現在の操業状態を保ちつつ経済運転を実現 したい。すなわち払出白色度の品質を保ちつつ高価な薬液で ある $\mathrm{ClO}_{2}$ 使用量を削減することがひとつの目標となる。晒 工程はむだ時間が大きくまた多変数が影響しあった系である ことから MPC の適用が必要とされるプラントであると言え る。

\subsection{2 段への適用}

$3 \mathrm{BL}$ のシーケンスにおける $\mathrm{ClO}_{2}$ 晒段は D 1 段と D 2 段で あり, 現状操業における $\mathrm{D} 1$ 段と $\mathrm{D} 2$ 段の $\mathrm{ClO}_{2}$ 添加率の比 は約 5：1である。ここで我々はまず D 2 段に対し MPC 制 御を適用してみることとした。その主たる理由は最重要品質

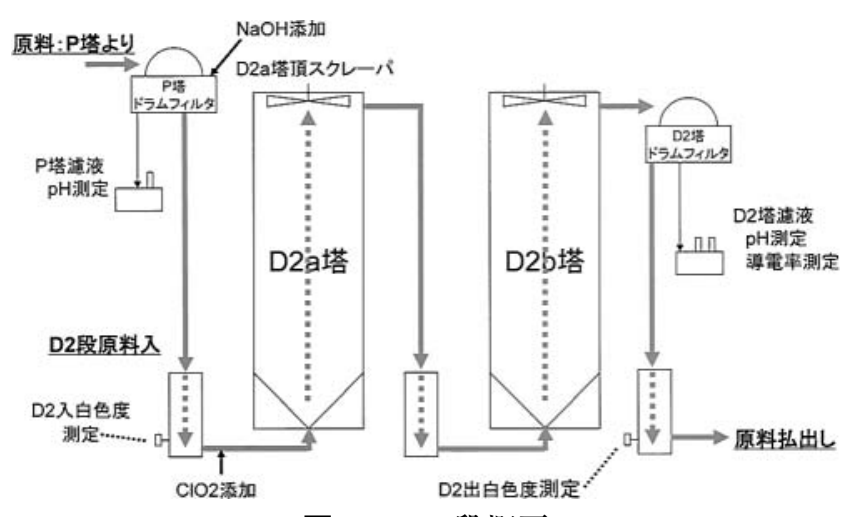

図 2 D 2 段概要

項目である払出白色度の安定確保に対する MPC の有効性を 計るためである。

まずここで，D 2 段の現状の制御について述べる。図 2 に D 2 段の概要を示す。

現状の DCS 制御における $\mathrm{ClO}_{2}$ 添加率の算出は以下のよう なアルゴリズムに従う。

まずオペレータが所望の D 2 段出白色度を設定する。DCS はこの設定值と D 2 段入白色度の測定值を比較し, D 2 段に おいて必要な白色度上昇の值を得る。この白色度上昇を得る に必要な $\mathrm{ClO}_{2}$ 添加率が, DCS 内部に持たされた関係式に従 って算出される。すなわち，この制御で用いられる測定值は D 2 入白色度のみである。

また, $\mathrm{ClO}_{2}$ を添加された原料の $\mathrm{pH}$ は添加率の上昇に伴っ て酸性の方向に進むが，強酸性に傾きすぎると $\mathrm{ClO}_{2}$ 晒の白 色度上昇の効果が悪化することが判っている。よって晒性能 の維持のためには $\mathrm{pH}$ の管理も重要である。D 2 段において は払出パルプの濾液の $\mathrm{pH}$ を管理している。現状の DCS 制 御において, 滤液 $\mathrm{pH}$ を設定值に一致させるに必要な $\mathrm{NaOH}$ 添加率は PID コントローラで求められる。

以上のように，現状の DCS による制御則には白色度や $\mathrm{pH}$ に対し最も支配的なパラメ夕をそれぞれ含んでおり，現在こ の制御により操業はほぼ安定して行われている。しかし操業 条件は常に一定とは限らず，目標から外れることも多い。よ って実操業時にはオペレータの経験とデータによる調整が欠 かせないものとなる。

以上を踏まえて, MPC コントローラの構築のための D 2

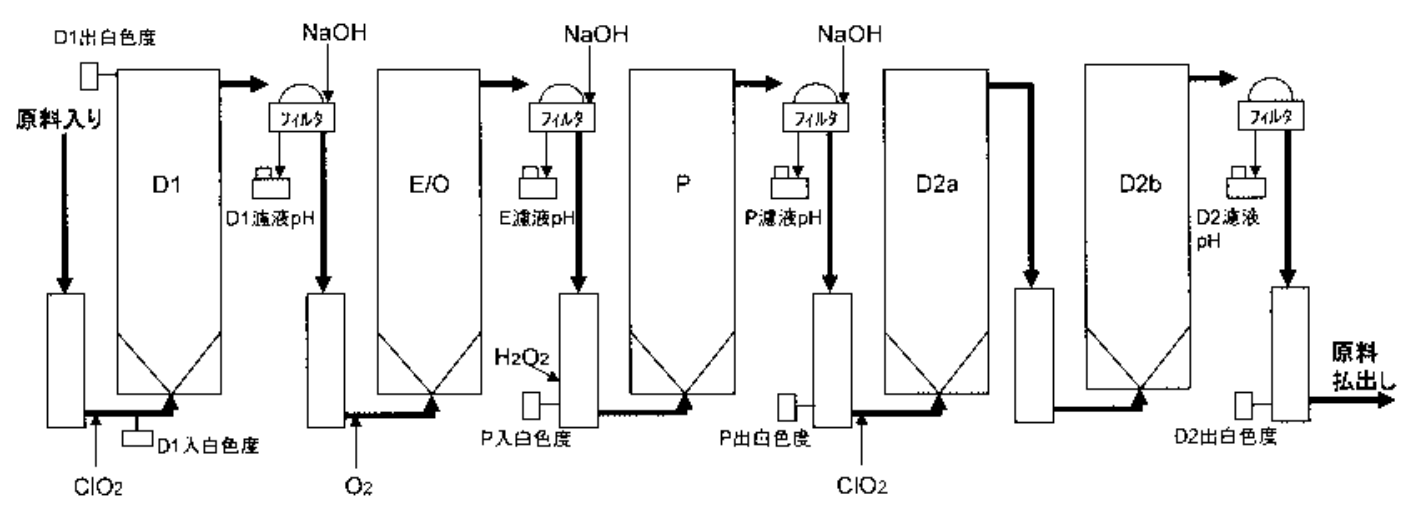

図 13 BL 概要 
段のモデルを作成する。すなわち「何を制御したいか＝制御 対象」と，それらを「何を使って制御したいか＝制御端，外 乱」を定め, それらの間の「入出力関係 $=$ 伝達関数」を求め る，という手順である。

まず「何を制御したいか」を定める。

晒工程の目的からして当然, D 2 出白色度が主要な制御対 象である。また上で述べたように, 濾液 $\mathrm{pH}$ の管理も重要で ある。これら現状 DCS で制御されている項目に加えて，二 酸化塩素晒においては残塩の管理も重要である。滤液の導電 率が滤液中 $\mathrm{ClO}_{2}$ 濃度と強い相関を持つことから, 残塩計の 代用として濾液導電率計を用いる。以上より，D 2 塔におい て制御すべき項目を「D 2 塔出白色度」, 「D 2 塔濾液 $\mathrm{pH} 」$, 「D 2 塔濾液導電率」とし, これらそれぞれに制御目標を定 めて，それぞれについて多変数制御を行うこととする。

つぎにこれら制御対象を「何を使って制御するか」を定め る。

まず D 2 塔出白色度についてである。操作量は従来の制御 と同じく $「 \mathrm{ClO}_{2}$ 添加率」とする。外乱として最も重要なの はこれも従来と同じく，白色度に大きく影響を及ぼす「D 2 塔入白色度」である。また今回はこれに加えて原料濃度の変 化を検知するパラメタとして「D $2 \mathrm{a}$ 塔頂スクレーパ消費電 流」も外乱として採用することにする。

次に D 2 塔濾液 $\mathrm{pH}$ の制御について考える。従来の制御で は $\mathrm{pH}$ の低下を外乱とみなし, $\mathrm{pH}$ 上昇の効果を持つ $\mathrm{NaOH}$ 添加率のみを操作量として制御してきた。しかし前節で述べ たように $\mathrm{pH}$ 低下は $\mathrm{ClO}_{2}$ 添加率にも影響される。そこで今 回は $\left\lceil\mathrm{ClO}_{2}\right.$ 添加率」と $\lceil\mathrm{NaOH}$ 添加率」の双方を操作量と する。また, D 2 塔入原料 $\mathrm{pH}$ 相当として前段の $\mathrm{P}$ 塔濾液 $\mathrm{pH}$ も外乱として取り込んだ。

以上のように決定された構造に従い，操作量および外乱そ れぞれから制御対象への伝達関数を求め, それを組み合わせ ることでモデルは構成される。 $\mathrm{ClO}_{2}$ 添加率 $\rightarrow \mathrm{D} 2$ 出原料白色 度, $\mathrm{ClO}_{2}$ 添加率 $\rightarrow \mathrm{D} 2$ 出濾液 $\mathrm{pH}, \mathrm{ClO}_{2}$ 添加率 $\rightarrow \mathrm{D} 2$ 出濾液 導電率, $\mathrm{NaOH}$ 添加率 $\rightarrow \mathrm{D} 2$ 出濾液 $\mathrm{pH}$ についてはそれぞれ $\mathrm{ClO}_{2}$ 添加率および $\mathrm{NaOH}$ 添加率のステップ応答テストを行 い，そのデータを用いたシステム同定結果から伝達関数を得 た。図 3 は $\mathrm{ClO}_{2}$ 添加率ステップ応答テストに対する各パラ

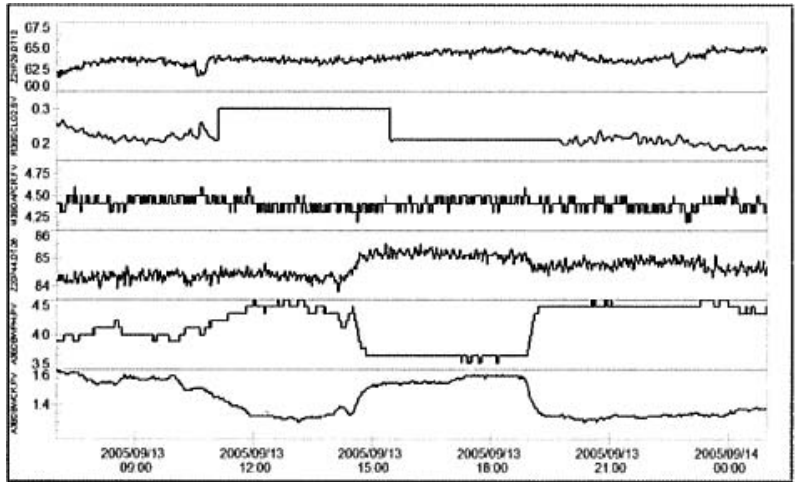

上段より $\mathrm{D} 2$ 塔入白色度, $\mathrm{D} 2 \mathrm{a}$ 塔 $\mathrm{ClO}_{2}$ 添加率, $\mathrm{D} 2 \mathrm{a}$ 塔項スクレーパ消費電 流, D 2 塔出白色度, D 2 塔滤液 $\mathrm{pH}, \mathrm{D} 2$ 塔滤液導電率

図 $3 \mathrm{ClO}_{2}$ 添加率ステップ応答テスト

メ夕の変化の様子である（グラフ 2 段目がステップ状に変化 させた $\mathrm{ClO}_{2}$ 添加率)。

またその他の伝達関数に関してはステップ応答テストの実 行は困難なため，通常の操業データからシステム同定を行い モデルを得た。同定には Exasmoc パッケージの同定ツール AIDA を使用した。こうして得られた操作端および外乱それ ぞれから白色度への伝達関数を組み合わせて得られたモデル によるシミュレーションの様子が図 4 である。

以上のようにして得られた D 2 段の制御用モデルをまとめ ると図 5 のようになる。

得られたモデルを用いた MPC コントローラによる D 2 段 の白色度制御の結果を示す。図 6 は判り易いように D 2 入原 料白色度と D 2 出目標白色度をむだ時間分後ろにシフトして D 2 出原料白色度に重ねたグラフである。また図 7 は $\mathrm{ClO}_{2}$ 添加率の推移である。

反省点として，制御開始直後のパルプの白色度目標からの ズレが少々大きかったことが挙げられる。これは入白色度の 変動がたまたま大きかったことと，制御の開始直後で Exasmoc が持つ学習機能が十分に働いていなかったことが原因 として考えられる。ただしこのズレの大きさは最大で 0.4 ポ イント程度であり, 品質目標の基準である 0.5 ポイントの 範囲には含まれる程度ではある。

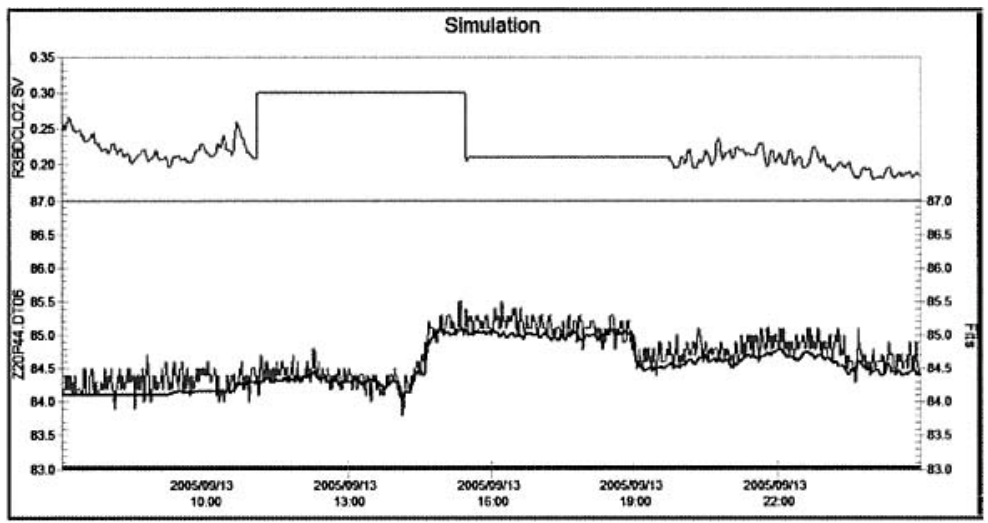

上段：D 2 a 塔 $\mathrm{ClO}_{2}$ 添加率

下段灰線：D 2 出白色度 下段黒線：シミュレーション結果

図 4 出白色度のシミュレーション 


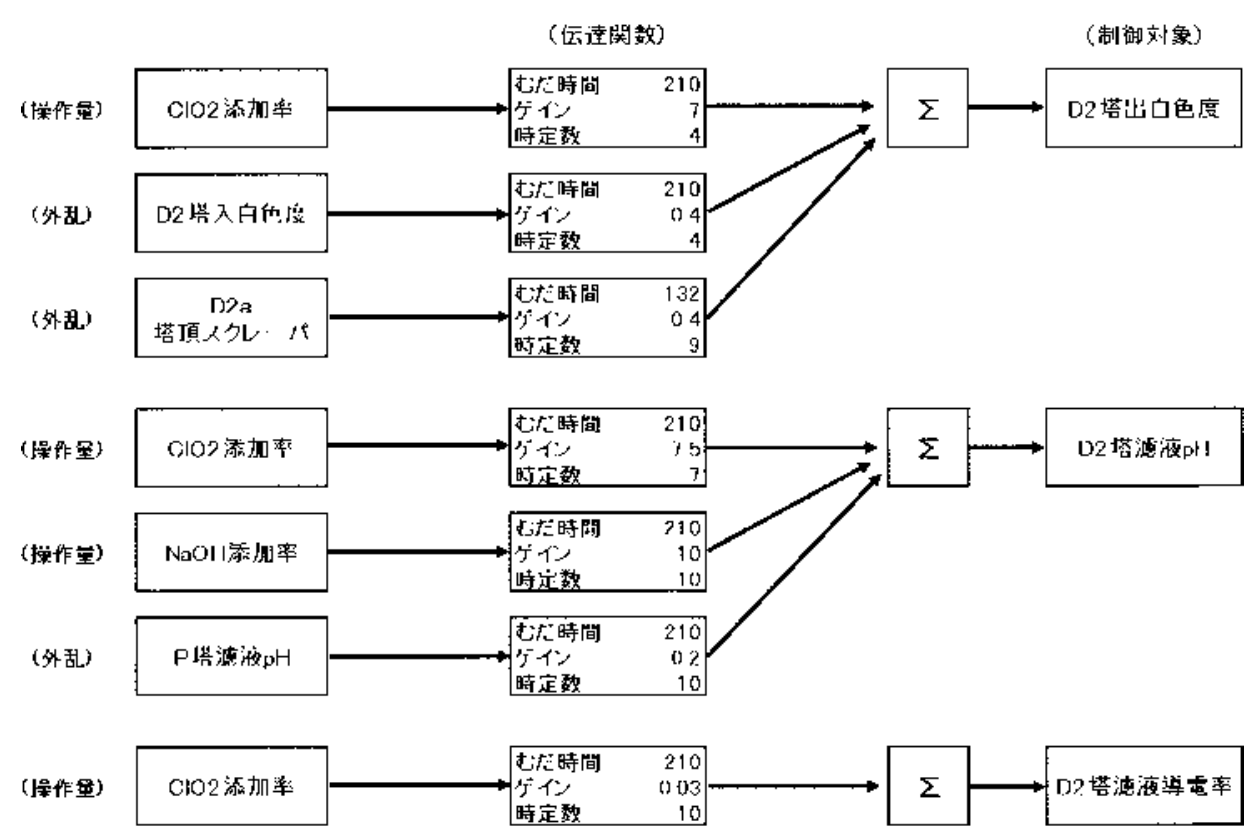

図 5 D 2 段 MPC 制御モデル

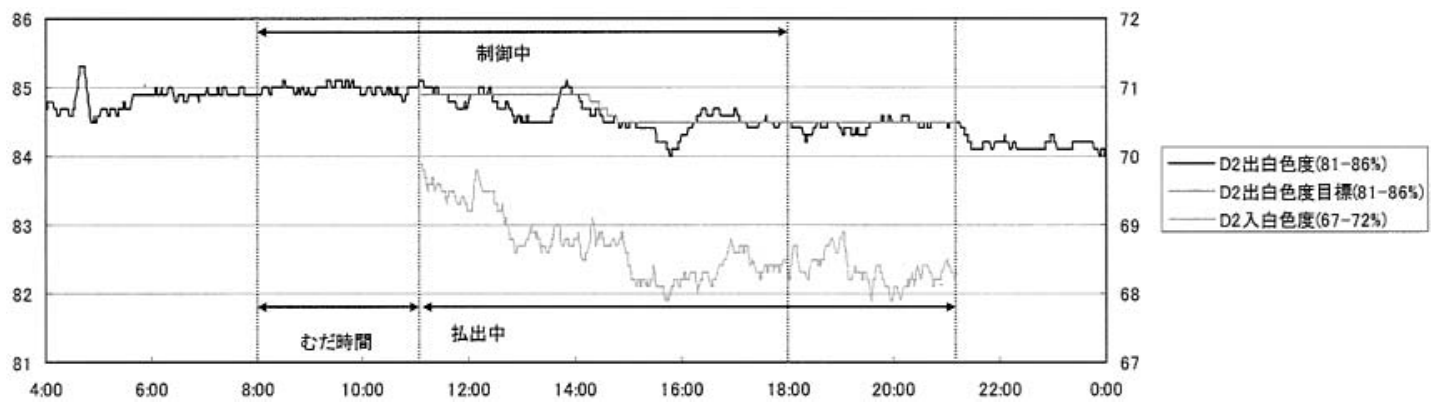

図 6 MPC 制御時の D 2 出白色度

D2a塔二酸化塩素添加率

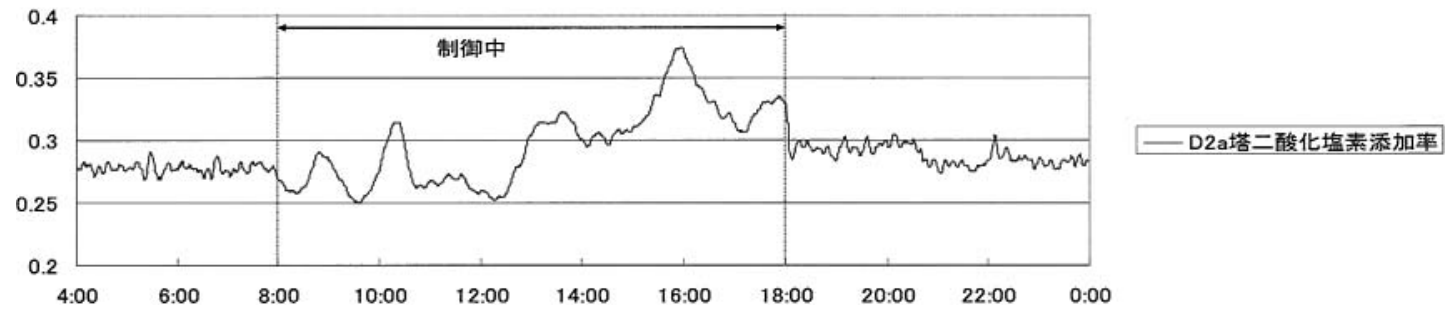

図 $7 \mathrm{MPC}$ 制御時の $\mathrm{ClO}_{2}$ 添加率推移

また概ね 16：00 以降は出白色度は目標にほぼ追従してい る。これは制御テスト開始から 8 時間程経っており, Exas$\operatorname{moc}$ の持つ自動修正機能も効いてきた為と思われる。16： 00 から制御終了時点の原料が出る $21: 00$ までの D 2 出白色 度の $1 \sigma$ は 0.106 , テスト直前の $1 \sigma$ は 0.158 と, MPC の適 用により白色度のばらつきに改善がみられ, MPCによる白 色度の制御が有効であることが確認できた。

\section{2 プラント全体の制御と最適化}

前項において，D 2 段への適用により白色度制御に対する $\mathrm{MPC}$ の有効性は確認できた。そこで次に経済運転の実現の ために，3 BL プラント全体への適用に着手した。
図 6 のトレンドからもわかるように，D 2 入の白色度はば らつきが激しい。よって上流に MPC 制御を施すことで D 2 入白色度を一定させるだけでもより一層の D 2 出白色度の安 定化を図ることができるとともに，D 2 段における $\mathrm{ClO}_{2}$ の 過剩添加も避けられ， $\mathrm{ClO}_{2}$ 添加率削減に寄与できる。また， 各段での白色度上昇分の分担を見直すことでより $\mathrm{ClO}_{2}$ 添加 率を削減できる可能性がある。

そこで，現在の操業の特徴から，3 BL を D 1 段， [E/O-P ] 段，D 2 段の 3 つのブロックに分けそれにそった制御モデル の構成を考えている。白色度のモデルのみを書いたものが図 8である。ただし，ここに記したのは特に支配的なパラメ夕 


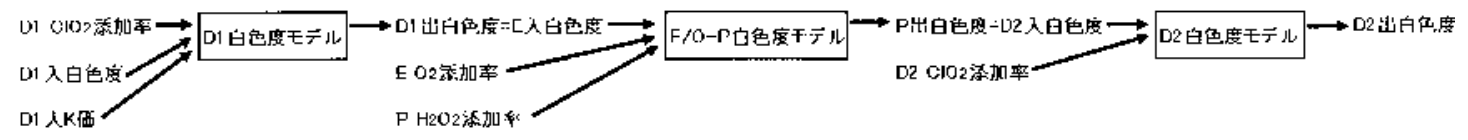

図 83 BL 白色度モデル概念

のみであり，原料濃度等，晒性に関係あると考えられる他の 外乱に関しては別途検討が必要となる

この構成は各ブロックの出力を後段へと順に渡していく形 になっているため, 各ブロックの白色度目標を調整すること により次段の薬液添加率に影響を及ぼしながらコントロール していくことができる。すなわち各ブロックでの出力を MPC 制御によって各々の目標に厳密に追従させることにより, 品 質の安定化と薬液添加率削減による経済効果を狙うことがで きるようになると考える。

5. まと め

本稿では MPC 制御による晒プラントの制御の取り組みに
ついて述べた。まず $\mathrm{N}$ 系晒設備（3 BL）の最終 $\mathrm{ClO}_{2}$ 晒段で ある D 2 段への適用の結果を示し, 白色度安定化制御に効果 があることを示した。そして, 経済運転の実現のため, $3 \mathrm{BL}$ 全体の MPC 制御の適用へと着手していることを述べた。今 後の取り組みとして, MPCにより $3 \mathrm{BL}$ の品質の安定を保 持しつつ薬液コスト削減を実現すること, また更なる目標と して当工場の L 系晒設備 (4 BL) への水平展開も考えてい きたい。

\section{Reference}

1) Yokogawa Electric Corporation: EXASMOC Online Multivariable Model Predictive and Optimizing Controller Operation Manual IM 36 J 06 D 11-01E (2004) 